\title{
Barium peritonitis: a near-fatal complication following a distal loopogram
}

\author{
Gorrepati Rohith (1) , Souradeep Dutta (1) , Rajkumar Nagarajan, \\ Kadambari Dharanipragada
}

Department of Surgery, Jawaharlal Institute of Postgraduate Medical Education and Research, Puducherry, India

Correspondence to Dr Rajkumar Nagarajan; raj.jipmer@gmail.com

Accepted 3 November 2020

\section{DESCRIPTION}

A 57-year-old man was admitted for ileostomy closure in a tertiary care centre in South India. Ileostomy was done 6 weeks ago for gangrene of distal $150 \mathrm{~cm}$ of ileum due to atherosclerosis of superior mesenteric artery. The gangrenous segment of the bowel was resected, and the ends were brought out as stoma. A distal loopogram was planned before ileostomy closure to assess the patency of the distal bowel. Pre-procedure, the patient was given distal loop and rectal washes with normal saline to clear the contents of the distal bowel. Barium $(100 \mathrm{~mL})$ was used as a contrast material for the study, and it was instilled through the distal mucous fistula via a Foley catheter (figure 1A). Fluoroscopy showed the passage of contrast through the distal loop till rectum without any hindrance, and the patient eventually excreted the contrast. The patient was stable all throughout the procedure. On the second postprocedural day, he developed tachycardia and hypotension with signs of peritonitis such as abdominal guarding and rigidity. He was stabilised with intravenous fluids and a plain abdominal X-ray was taken, which showed extravasation of contrast in the pelvis (figure 1B). An emergency exploratory laparotomy showed extravasated barium in the peritoneal cavity densely adhering to the parietal layer of the abdomen and bowel wall (figure 1C,D). A perforation was found $15 \mathrm{~cm}$ distal to the cutaneous end of the distal mucous fistula, probably resulting from an ischaemic insult to the bowel wall either due to the pre-existing bowel condition per se or an iatrogenic injury during the previous surgery. ${ }^{12}$ The stoma was dismantled, the bowel segment distal to the perforation was resected and a redo stoma was performed after thorough lavage. Histopathology revealed barium stains on the resected bowel loop with a perforation, and viable mucosal ends. $\mathrm{He}$ recovered uneventfully and passed hard barium pellets for the next 1 month.

Barium sulfate suspension, although inert inside the bowel, its accidental spillage into peritoneal cavity causes a severe inflammatory reaction that is associated with 35\%-50\% mortality. ${ }^{3}$ It causes peritonitis in the acute setting and baryoma (barium stone) formation along with recurrent episodes of intestinal obstruction in chronic cases. ${ }^{4}$ The acute phase can be complicated by faecal spillage which in the present case was
Check for updates

(C) BMJ Publishing Group Limited 2020. No commercial re-use. See rights and permissions. Published by BMJ.

To cite: Rohith G, Dutta $S$, Nagarajan $\mathrm{R}$, et al. BMJ Case Rep 2020;13:e239351. doi:10.1136/bcr-2020 239351

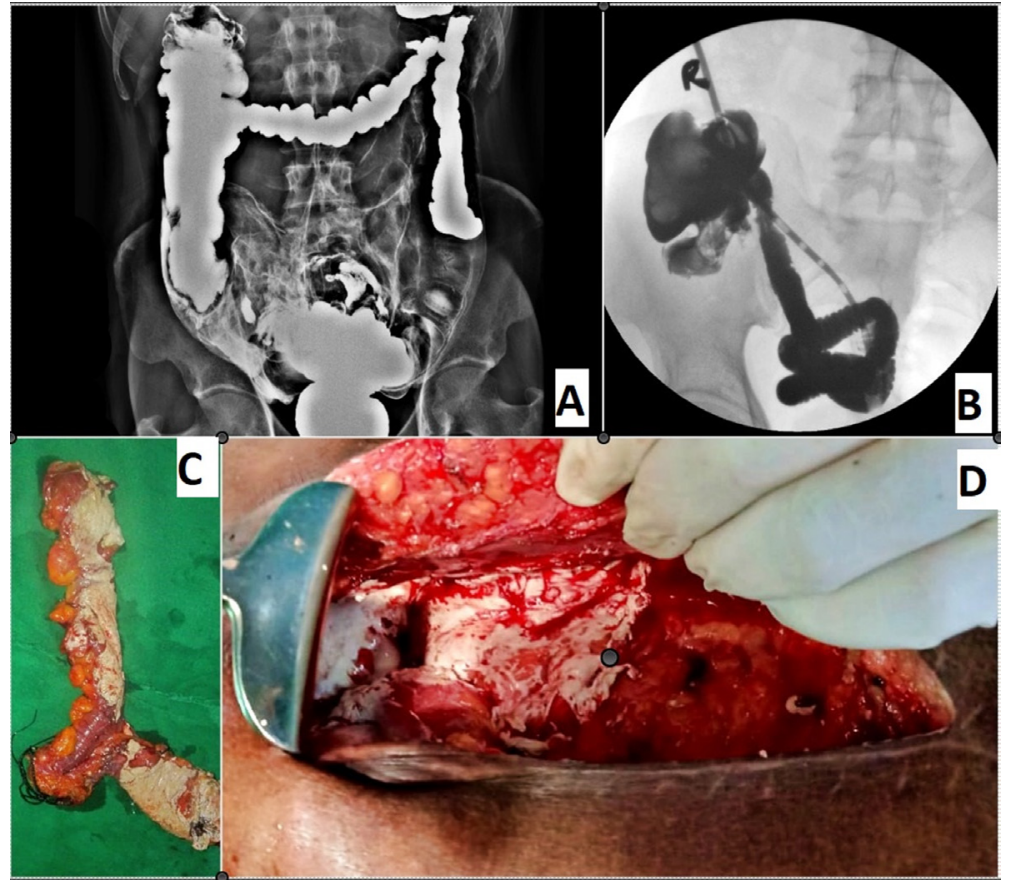

Figure 1 (A) Abdominal X-ray showing contrast collection in the pelvis and barium flakes outside the bowel wall. (B) Fluoroscopic image showing instillation of barium suspension through the distal loop of ileostomy. (C) Resected specimen showing barium-coated bowel loop along with the excised stoma. (D) Barium-coated parietal wall of the abdomen. 


\section{Patient's perspective}

I went through a major abdominal surgery 6 weeks ago as a part of my intestine had gangrene which I was told was because of atherosclerosis, something which I developed due to my old age and smoking habit. They brought a part of my bowel and stuck it to my abdomen outside through which I passed stools, which used to come out continuously and in large quantities. It was very embarrassing for me to go out with this and I mostly stayed indoors. My wife had to change the bag daily and at times twice a day. I wanted to get rid of it at any cost. Doctors said I had to wait for 6 weeks minimum for the stoma to mature such that they can safely go in and repair it. I was finally admitted for the stoma reversal surgery after 6 weeks and I was glad that all my problems would come to an end. The next day, I was told that I had to get a test done through which they are going to check the part of bowel after the stoma is healthy or had any problems like strictures. They said they would put a contrast liquid into the stoma and see where it goes through $X$-rays. I agreed to that and I was wheeled into the X-ray room. They made me lie down and removed the stoma bag. I was surprised as the technician did not even flinch when the foul smell filled the room as soon as the bag was removed. May be they do this every day. One of the doctors came in and put a tube into the intestine and injected a liquid. After injecting some amount, I had an urge to pass stool. I was embarrassed but the doctor assured me it's okay and they wanted me to pass stools to complete the test. I passed a whitish liquid that they injected. The doctor smiled at me and said we can proceed with the surgery. I passed more of the liquid after 2 hours. I developed vague pain at the site of stoma but neglected it as I thought it was because of the doctor's handling. The next day, the pain became even worse and I started feeling giddy. I was immediately taken to the X-ray room and after that they told me that there was some problem that had occurred because of the previous day's procedure and I should be operated on immediately. I was in severe pain and decided to comply to save myself. They wheeled me to the same emergency operating theatre and operated on me.

The next day I woke up and felt vague pain at the surgery site. I was told I was safe and the operation went well. Two days later, I passed hard white pellets and they were painful to pass. The doctor who operated on me extensively explained to me about barium peritonitis that was responsible for the sudden deterioration. I was depressed on seeing the turn of events, and also realising the stoma closure could not be performed. I was given psychologist's consultation and I was shifted back to the ward the next day. I began eating 4 days after the surgery and was passing hard pellets of barium along with the stools and it was very painful. I was given anaesthetising ointment along with stool softeners which helped a little bit. I was discharged 10 days post procedure and cannot thank enough the doctors who took care of me in my testing times.

absent due to preprocedural preparation. Nevertheless, barium itself draws fluid into the peritoneum, causing severe hypotension, needing aggressive intravenous fluid resuscitation. ${ }^{3}$ Early laparotomy and lavage with copious amounts of normal saline are advocated. ${ }^{5}$
The barium forms clumps with fibrin-rich substrates which adhere strongly to the parietal wall and bowel surfaces. Attempts to remove them increases the chances of future adhesive intestinal obstruction. ${ }^{3}$ The perforation site should be identified, and the choice of primary closure versus resection of the segment with or without proximal stoma should be taken based on the degree of contamination. ${ }^{6}$ The greater omentum should be sacrificed to reduce the barium load, and antibiotics have to be administered in the postoperative period to tackle the faecal contamination. ${ }^{3}$ Adequate precautions should be taken while instilling contrast into the bowel loop, and a water-soluble contrast medium should be preferred. Preprocedural per-stomal examination should be performed to assess bowel wall integrity. As the small bowel is less distendable, soft, straight tubes without retention balloons should be used. Manual compression on the outer surface of stoma using a balloon or cone should be used to aid contrast retention. ${ }^{2}$

\section{Learning points}

- Barium peritonitis is a rare but severe complication of gastrointestinal contrast studies. Adequate fluid resuscitation, early laparotomy and lavage with copious amounts of normal saline, and postoperative antibiotic administration forms the mainstay of treatment.

- Barium densely adheres to the bowel wall, and overzealous scrapping of these flakes is strictly discouraged.

- Careful technique of using straight and soft tubes for contrast instillation and avoiding intraluminal inflation of retention balloon is needed to avoid this grave complication.

- Water-soluble contrast materials are to be used for checking the patency of distal bowel loop for stoma reversal rather than barium sulfate suspension as they cause less peritoneal irritation than barium in a case of accidental perforation.

Twitter Souradeep Dutta @souradeep

Contributors Concept and design: GR and RN. Data acquisition and analysis, manuscript preparation: SD and GR. Critical revision and finalising of the manuscript: RN and KD.

Funding The authors have not declared a specific grant for this research from any funding agency in the public, commercial or not-for-profit sectors.

Competing interests None declared.

Patient consent for publication Obtained.

Provenance and peer review Not commissioned; externally peer reviewed.

\section{ORCID iDs}

Gorrepati Rohith http://orcid.org/0000-0003-1081-027X

Souradeep Dutta http://orcid.org/0000-0002-1600-3439

\section{REFERENCES}

1 de Miranda CLVM, de Sousa CSM, Cordão NGNP, et al. Intestinal perforation: an unusual complication of barium enema. Radiol Bras 2017;50:339-40.

2 Williams SM, Harned RK. Recognition and prevention of barium enema complications. Curr Probl Diagn Radiol 1991;20:126-51.

3 Karanikas ID, Kakoulidis DD, Gouvas ZT, et al. Barium peritonitis: a rare complication of upper gastrointestinal contrast investigation. Postgrad Med J 1997;73:297-8.

4 Alwalid 0, Shen X. Gastrointestinal and peritoneal barium granulomas in old patient. J Belg Soc Radiol 2020;104:15.

5 Westfall RH, Nelson RH, Musselman MM. Barium peritonitis. Am J Surg 1966;112:760-3.

6 Pandit N, Singh H, Jaiswal LS. Barium peritonitis: a disastrous complication of an unnecessary diagnostic study. Trop Doct 2018;48:171-3. 
Copyright 2020 BMJ Publishing Group. All rights reserved. For permission to reuse any of this content visit https://www.bmj.com/company/products-services/rights-and-licensing/permissions/

BMJ Case Report Fellows may re-use this article for personal use and teaching without any further permission.

Become a Fellow of BMJ Case Reports today and you can:

- Submit as many cases as you like

- Enjoy fast sympathetic peer review and rapid publication of accepted articles

Access all the published articles

Re-use any of the published material for personal use and teaching without further permission

Customer Service

If you have any further queries about your subscription, please contact our customer services team on +44 (0) 2071111105 or via email at support@bmj.com.

Visit casereports.bmj.com for more articles like this and to become a Fellow 